\section{Erratum to: On Morley's Trisector Theorem}

The online version of the original article can be found under doi:10.1007/s00283-014-9463-3.

\section{Erratum to: The Mathematical Intelligencer DOI 10.1007/s00283-014-9463-3 Published 36-3 page 3}

$7 \mathrm{n}$ her preface to John Conway's note "On Morley's Trisector Theorem" (Vol. 36, no. 3, p. 3) the editor remarked that Conway's proof is "out there" yet nowhere in print. In fact Martin Gardner discussed it in Sphere Packings, Lewis Carroll, and Recursi, Cambridge University Press, 2009, pp. 229-230.

Springer regrets the error.

USA

e-mail: ryba@sylow.cs.qc.cuny.edu 